\title{
The Suitability of Porous Material to Simulate Evaporation in Human Sweating Mechanisms
}

\author{
Rhubenthiraan Kelundapyan, Lee Yee Yong, Mohd Azuan Zakaria, Sasitharan Nagapan, \\ Viknheswar Chandira Segaran
}

\begin{abstract}
This study aims to determine the suitable porous material that can simulate human sweat evaporation rate for preliminary thermal comfort assessment. The objective of the study was to identify the relationship of human sweat evaporation rate with porous material evaporation rate. Field experimental has been conducted to measure the evaporation rate of porous material such as red clay, white clay, plaster and human sweat. Then, the correlation analysis was conducted between porous material evaporation rate and human sweat evaporation rate. The collected data were analyzed by using SPSS 20 and Microsoft Excel 2016 tools. Pearson correlation were used as statistical analysis to find the relationship between both variable. The statistical significance level was set at $P<$ 0.01 . Based on the findings, human sweat evaporation rate had a moderate correlation with red clay $(r=0.583)$ and white clay $(r=$ $0.503)$ with statistically significant but very weak correlation with plaster $(r=0.020)$. The porous characteristics of red clay and white clay has the capillary effect which is almost like human skin by showing a good correlation between human sweat and porous material evaporation rate. As this is preliminary study, in future more research to be done to obtain higher correlation between porous material and the human body by modifying the material. To minimize heat stress, it would be a step forward in evaluating outdoor thermal comfort and raising awareness of society and government.
\end{abstract}

Keywords: Human Sweat Loss, Porous Material, Thermal Comfort, Thermal Manikin

\section{INTRODUCTION}

The world is growing towards urbanization and it is an alarming social issue for the developing countries [1]. With growing urbanization, the phenomenon of Urban Heat Island (UHI) is becoming more of a concern, with the intensity of

Revised Manuscript Received on February 05, 2020.

* Correspondence Author

Rhubenthiraan Kelundapyan, Faculty of Civil and Environmental Engineering, Universiti Tun Hussein Onn Malaysia, Johor, Malaysia.

Lee Yee Yong, Department of Civil Engineering, Faculty of Engineering Universiti Malaysia Sarawak, Kota Samarahan, Malaysia.

Mohd Azuan Zakaria, Faculty of Civil and Environmental Engineering, Universiti Tun Hussein Onn Malaysia, Johor, Malaysia.

Sasitharan Nagapan, Faculty of Civil and Environmental Engineering, Universiti Tun Hussein Onn Malaysia, Johor, Malaysia.

Viknheswar Chandira Segaran, Faculty of Civil and Environmental Engineering, Universiti Tun Hussein Onn Malaysia, Johor, Malaysia.

(C) The Authors. Published by Blue Eyes Intelligence Engineering and Sciences Publication (BEIESP). This is an open access article under the CC BY-NC-ND license (http://creativecommons.org/licenses/by-nc-nd/4.0/)
UHI is increasing, particularly in many megacities [2]. A UHI is known as a climatic phenomenon in which urban areas have higher air temperature than their surrounding rural area. The UHI effect can caused a person to experience thermal discomfort and likely to expose to heat health illness specially at outdoor condition. Frequent exposure to the heated environment will thus contribute to a decrease in thermal comfort, thus increasing the prevalence of heat-related illness [3]. Therefore, it is essential to evaluate hot environments in order to ensure the health and safety of outdoor individuals [4].

In order to keep people away from heat and discomfort, mitigation and prevention strategies should be introduced. In the aspect of heat stress assessment, the direct method of exposing the human body to direct sunlight or evaluating outdoor thermal comfort is discouraged due to health problem. Therefore, in combination with these mitigation initiatives, the development of thermal manikin in the future research may be useful as a representative of the human simulation model to investigate the occurrence of UHI and to assess thermal comfort under microclimate conditions [5]. The purpose of thermal manikin is to evaluate the effect of human body and simulate human responses in thermal environments [6]. The number of thermal sweating manikins has steadily increased, and many modern thermal manikins are designed with a sweating feature [7]. Since the development of thermal manikin is getting more and more attention, it is possible to include the combination of human factors such as physiological mechanism of thermoregulation by fabricating thermal manikin, thermal sensation by questionnaire survey and thermal comfort indices based on meteorological data to evaluate human thermal comfort in outdoor environment [8]. Therefore, in this study, the porous material will be assess based on human sweat evaporation rate which is indicating physiology.

Based on previous study, there's a lot of sweating manikin has been used worldwide with different material [9]. There is lack manikin that made up from red clay, white clay and plaster till date. However, in 2004, Mendes \& Silva had used the porous material of plaster, white clay and red clay to simulate human perspiration and they stated that the porous material has the capillary effect and formation of a humid layer on the external surface of the porous material which is almost similar to human skin. The porous material also has the characteristics such as cooling effect and the evaporation rate based on air temperature is almost same with human skin [10]. 
Porous materials have shown the capacity to simulate evaporation in human sweating mechanism based on theory. But the researcher never used actual human sweat loss and compare with the porous material. The knowledge gap is existing there. Hence, the aim of this study focused on the investigation of the suitability of porous material such as red clay, white clay and plaster that can simulate human sweating mechanisms. This research was used as a preliminary study to examine the suitability of porous material to become the material in developing the heat indicator for a new generation of manikin suitable for outdoor environments.

\section{MATERIAL AND METHOD}

\section{A. Material Fabrication and Preparation}

There is a lot of technique to fabricate the material, such as using mould, hand-construction, using potter wheel, roller head machine, granulate pressing, etc. Fabricating using mould has been selected for this study. Mould fabrication technique is precise and accurate in comparison with other methods because each and every material should be of the same dimension in these studies. Four unglazed pot for each red clay, white clay and plaster pots were prepared. The unglazed pots were used due to its porosity characteristic. The four unglazed pots for each kind of material were prepared with the same dimension. However, the dimension for plaster is slightly thicker from the other materials due to its characteristics. The pots were used to determine the evaporation rate by getting the average value for data reliability. Table 1 shows the overall calculated surface area for the porous material. Red clay and white clay are fabricated in the shape of barrel. The barrel surface area can be calculated by using formula, as shows in equation in 1 . Meanwhile, the plaster is in shape of conical frustrum due to its porous characteristics. The conical frustum surface area can be calculated by using the formula, as shown in equation 2 . The Figure 1 shows the type of porous material.

$$
\text { Barrel surface area }=\left[\left(\pi \times\left(\left(2 \times R^{2}\right)+r^{2}\right)\right) \div 3\right]
$$

Conical frustum surface area $=\left[\pi(r+R) \sqrt{ } h^{2}+(R-r)^{2}\right]$

Where $\mathbf{R}$ is middle radius and $\mathbf{r}$ is top/bottom radius.

Table 1: Surface area of the porous material

\begin{tabular}{|c|c|c|c|c|}
\hline $\begin{array}{c}\text { Type of Porous } \\
\text { Material }\end{array}$ & $\begin{array}{c}\text { Height } \\
(\mathbf{m})\end{array}$ & $\mathbf{R}(\mathbf{m})$ & $\mathbf{r}(\mathbf{m})$ & $\begin{array}{c}\text { Surface Area } \\
\text { of plaster }\left(\mathbf{m}^{\mathbf{2}}\right)\end{array}$ \\
\hline Red Clay & 0.113 & 0.0505 & 0.039 & 0.006938 \\
\hline White Clay & 0.112 & 0.0505 & 0.039 & 0.006938 \\
\hline Plaster & 0.108 & 0.05 & 0.04 & 0.03067 \\
\hline
\end{tabular}

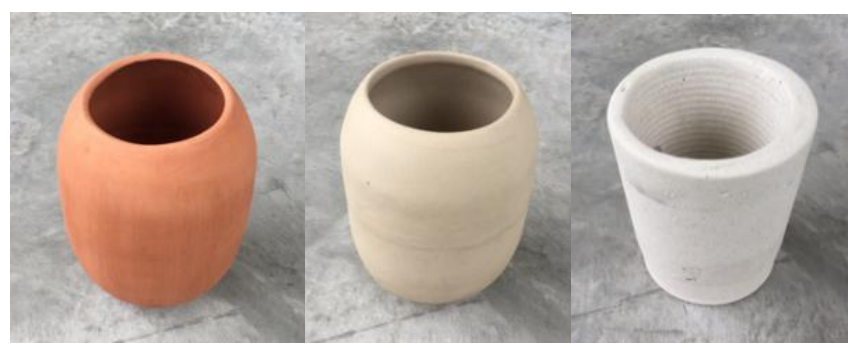

Fig. 1. Type of porous material

\section{B. Study Area}

Malaysia is known as tropical country with hot and humid climate [12]. The daily average air temperature ranges from $24^{\circ} \mathrm{C}$ to $38^{\circ} \mathrm{C}$, whereas the minimum temperature is normally reported during the night. The relative humidity ranging from $70 \%$ to $90 \%$ throughout a year, it may differ at different locations [13]. Therefore, these climatic features characterize as tropical environment in Malaysia. This study was conducted at University Teknologi Malaysia (UTM, $1^{\circ} 33^{\prime} 51.7^{\prime \prime} \mathrm{N}, 103^{\circ} 37^{\prime} 43.5^{\prime}$ 'E). In the experiment, the rate of evaporation of porous materials under solar thermal / sunlight exposure were measured to simulate human sweating mechanisms for thermal comfort assessment.

\section{Experiment Procedure}

The field investigations of this study were conducted on January $9^{\text {th }}$ to $16^{\text {th }} 2019$ in the UTM campus from 9.00 am to $6.00 \mathrm{pm}$. The experiment was carried out for 7 days continuously. Four unglazed of each material pots were immersed in water for few days until the weight of the pots were constant to ensure the pots were in saturation state before the experiment was carried out. After that, all the pots from different material were placed in open spaces under exposure of sunlight in open area. The pots were filled with water and covered. The purpose of the cover was to make sure the water does not evaporate through the opening. The weights of the pots were measured and recorded every 15 minutes start from 9.00 a.m. until 6.00 p.m. in order to calculate the evaporation rate. Furthermore, the microclimatic variable was measured and recorded every 15 minutes parallel with the experiment carried out. Meantime, human sweat evaporation rate also been obtaining simultaneously with pots evaporation rate for every 15 minutes in this study. Figure 2 shows the measurement of human and porous material by using high precision balance scale.
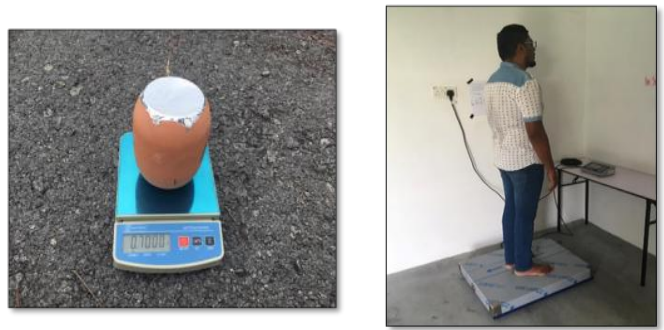

Fig. 2. Measurement of human and porous material by using electric precision balance scale 
Sweat evaporation rate for human subject is calculated using Peter-Pass More equation. Meanwhile, for porous material, the evaporation loss will be obtained thru Mendes and Silva equation. Human and pots weight will measure using electronic precision balance (accuracy of $1 \mathrm{~g}$ ). Metabolic rate and clothing insulation are calculated in compliance with ASHRAE standard 55-2017 [14]. The correlation between both parameters is an early step to determine the suitable material for that can represent human sweating mechanisms.

\section{Microclimate Measurement}

Microclimatic data were reported with respect to air temperature, relative humidity, wind speed and solar radiation through Delta Ohm data loggers (HD35EDL instrument). The data loggers were set to acquire data at 15-minute intervals automatically at a height of $2 \mathrm{~m}$ above the ground.

Table 2 shows the sensors specifications that were used to measure the micrometeorological parameters at site in accordance with ISO 7726 [15].

Table 2: Specifications and Measurement Range

\begin{tabular}{|l|l|l|l|}
\hline Parameter & $\begin{array}{l}\text { Brand \& } \\
\text { Model }\end{array}$ & $\begin{array}{l}\text { Measuring } \\
\text { range }\end{array}$ & Resolution \\
\hline Air temperature & $\begin{array}{l}\text { Delta OHM, } \\
\text { HD35EDL }\end{array}$ & $-40 \ldots+105^{\circ} \mathrm{C}$ & $0.1^{\circ} \mathrm{C}$ \\
\hline Relative humidity & $\begin{array}{l}\text { Delta OHM, } \\
\text { HD35EDL }\end{array}$ & $0 \ldots .100 \% \mathrm{RH}$ & $0.1^{\circ} \mathrm{C}$ \\
\hline Wind speed & $\begin{array}{l}\text { Delta OHM, } \\
\text { HD35EDL }\end{array}$ & $0 \ldots 65 \mathrm{~m} / \mathrm{s}$ & $0.1 \mathrm{~m} / \mathrm{s}$ \\
\hline Solar radiation & $\begin{array}{l}\text { Delta OHM, } \\
\text { HD35EDL }\end{array}$ & $\begin{array}{l}0 \ldots 2000 \\
\mathrm{~W} / \mathrm{m}^{2}\end{array}$ & $1 \mathrm{~W} / \mathrm{m}^{2}$ \\
\hline
\end{tabular}

\section{E. Measurement and Calculation}

\section{Determination of Evaporation Rate of Porous Material}

The evaporation rate was calculated using the Equation (3) which stated in the study of [10] and the graph was draw with respect to time.

$$
S_{W}=3.6 \times 10^{6} \frac{\Delta P}{A s \Delta t}
$$

Where $\Delta P$ is the weight loss $(\mathrm{kg}), A_{s}\left(\mathrm{~m}^{2}\right)$ is the external surface area of the specimen tested and $\Delta t(\min )$ is the interval of time.

\section{Determination of Actual Human Sweat Evaporation Rate}

The sweat losses were calculated by considering the change in individual nude body weight $(\mathrm{kg})$ measured before and after each experiment on an electronic precision balance scale (1g accuracy). During the experiments, water from pre-measured bottles was available to drink at will. The weights of all food and water intake and urine voided were measured on an electronic scale (accuracy of $1 \mathrm{~g}$ ). The weight of any fecal mass was determined from body mass changes before and after void. Using the Peters-Passmore equation [16], total sweat losses were calculated by mass balance and then time weighted to derive rate. The measurements assume that $1 \mathrm{ml}$ of sweat is equal to a mass of $1 \mathrm{~g}$. Sweating rate expressed as liters $/ \mathrm{h}$ or $\mathrm{g} / \mathrm{m}^{2} . \mathrm{m}$ was determined by time and surface area weightings as appropriate. To summarizes, the following are the formula:

Total sweat loss $(\mathrm{kg})=$ changes in body mass + (solids in - solids out) + (fluids in - fluids out)

$$
S_{W}=\frac{\Delta P}{A s \Delta t}
$$

Where $\Delta P$ is the total sweat loss $(\mathrm{kg}), A_{s}\left(\mathrm{~m}^{2}\right)$ is the external surface area of the respondent tested and $\Delta t(\mathrm{~min})$ is the time interval.

\section{F. Statistical Analysis}

Microsoft Excel and the Social Sciences Statistical System (SPSS) 22 used statistical tests such as descriptive analysis and bivariate analysis (Pearson correlation) to analyze the data obtained. The statistical significance level was set at $\mathrm{P}<$ 0.01 .

\section{RESULT AND DISCUSSION}

\section{A. Microclimate Condition}

The statistical data of outdoor climate were recorded during the survey and provided in Table 3 which indicated the daily average, minimum and maximum values of measured micrometeoroogical variables.

The variables were measured simultaneously $9 \mathrm{am}$ to $6 \mathrm{pm}$ for 7 days.

Table 3: Weather Statistics of the Study Period at the Exposed Site

\begin{tabular}{|l|c|c|c|}
\hline & Min & Max & Mean \\
\hline Air temperature $\left({ }^{\circ} \mathrm{C}\right)$ & 26.6 & 34 & 30.55 \\
\hline Relative humidity (\%) & 45.4 & 89.3 & 65.10 \\
\hline Wind speed (m/s) & 0.3 & 3.8 & 1.34 \\
\hline Solar radiation $\left(\mathrm{W} / \mathrm{m}^{2}\right)$ & 61.0 & 1144.0 & 502.46 \\
\hline
\end{tabular}

\section{B. Porosity of the Material}

Porosity is defined as the ratio of volume of pores to the total volume of the material [11].

The purpose of the porosity test is to find to the porosity level and the effect of pores to this study.

Water Saturation Method is used to calculate the porosity percentage [11]. Table 4 shows the average of each porous material that using throughout the study.

As shown in the table, red clay has $7.6 \%$ of porosity. White clay shows the least porosity which indicate $2.8 \%$ only.

Meanwhile, plaster has the highest porosity percentage compare to other material which indicate $16.7 \%$.

The porosity of each material is depending on the material characteristic. 
Table 4: Porosity percentage of porous material

\begin{tabular}{|c|c|c|c|c|}
\hline & Minimum & Maximum & Mean & $\begin{array}{c}\text { Std. } \\
\text { Deviation }\end{array}$ \\
\hline $\begin{array}{c}\text { Human sweat } \\
\text { evaporation rate } \\
\text { (Kg/m².m) }\end{array}$ & .00092 & .00496 & .00291 & .00091 \\
\hline $\begin{array}{c}\text { Red clay evaporation } \\
\text { rate (Kg/m².m) }\end{array}$ & 14989.9 & 232920.1 & 109864.3 & 37780.9 \\
\hline $\begin{array}{c}\text { White clay evaporation } \\
\text { rate }\left(\mathrm{Kg} / \mathrm{m}^{2} . \mathrm{m}\right)\end{array}$ & 9253.9 & 92539.0 & 40762.1 & 18096.1 \\
\hline $\begin{array}{c}\text { Plaster evaporation rate } \\
\left(\mathrm{Kg} / \mathrm{m}^{2} . \mathrm{m}\right)\end{array}$ & 5477.7 & 115422.2 & 52060.3 & 27881.74 \\
\hline
\end{tabular}

\section{Relationship between Human Sweat and Porous Material Evaporation Rate}

In this study, the variation between human sweat and porous material evaporation rate must be present in order to understand the evaporation rate based on surrounding environment before moving to correlation. The variation is shown as average value throughout the study in Figure 3. Table 5 shows the minimum, maximum, mean and standard deviation value for human sweat and all porous material evaporation rate.

\section{Table 5: Descriptive statistics for Human Sweat and Porous Material Evaporation Rate Descriptive Statistics}

\begin{tabular}{|c|c|c|c|}
\hline & $\begin{array}{c}\text { Red Clay } \\
\text { Average }\end{array}$ & $\begin{array}{c}\text { White Clay } \\
\text { Average }\end{array}$ & $\begin{array}{c}\text { Plaster } \\
\text { Average }\end{array}$ \\
\hline $\begin{array}{c}\text { Saturated } \\
\text { Weight (g) }\end{array}$ & 375.2 & 370.7 & 524.3 \\
\hline $\begin{array}{c}\text { Dry Weight (g) } \\
\text { Total Weight } \\
\text { Loss (g) }\end{array}$ & 315.9 & 348.9 & 407.3 \\
\hline $\begin{array}{c}\text { Pore Volume } \\
\left(\mathrm{m}^{3}\right)\end{array}$ & 0.000059 & 21.8 & 117 \\
\hline $\begin{array}{c}\text { Total Volume } \\
\left(\mathrm{m}^{3}\right)\end{array}$ & 0.000784 & 0.000784 & 0.0007 \\
\hline $\begin{array}{c}\text { Porosity (\%) } \\
\text { (\%) }\end{array}$ & 7.6 & 2.8 & 16.7 \\
\hline
\end{tabular}

Figure 3 presents the overall average value of human sweat evaporation rate and the average evaporation rate for red clay, white clay and plaster. At start of the experiment which is at $9.15 \mathrm{am}$, the air temperature is recorded at 27.0 ${ }^{\circ} \mathrm{C}$, the human loss $0.00191 \mathrm{Kg} / \mathrm{m}^{2}$.m of sweat, red clay evaporate around $67070.3 \mathrm{Kg} / \mathrm{m}^{2} . \mathrm{m}$, white clay and plaster evaporate $29561.1 \mathrm{Kg} / \mathrm{m}^{2} . \mathrm{m}$ and $103684.4 \mathrm{Kg} / \mathrm{m}^{2} . \mathrm{m}$ respectively as shown in Figure 4 and 5. However, at 2.15pm the average air temperature increases to maximum temperature which is $31.9^{\circ} \mathrm{C}$, the evaporation rate for human sweat and porous material also increase except for plaster which shows $46727.8 \mathrm{Kg} / \mathrm{m}^{2} . \mathrm{m}$ of evaporation rate. At the end of the experiment, the temperature is decrease to $30{ }^{\circ} \mathrm{C}$ and the evaporation rate for human sweat and porous material also decreases. Different porous material has different evaporation mechanism due to its characteristics. Evaporation rates from porous media may vary considerably due to changes in internal transport mechanisms [17]. The two factors affecting the evaporation rate from porous media filled with water are atmospheric conditions such as air temperature, humidity and pore space properties [18]. Meanwhile, human sweating from the skin occurs only when the surrounding temperature is moderately high [19]. When the body becomes overheated, sweat is secreted onto the surface of the skin and is evaporated by the heat supplied by the skin surface [20]. The variation between human sweat and porous material eavporation rate as shown in Figure 4 and Figure 5 is corresponding to air temperature which can define as when the air temperature is increase, the evaporation rate of human sweat and porous material also increase. This can be proven by [21] which stated that an increasing in the air temperature enhances the cooling effect of evaporation in the porous material. However, under long-term exposure to hot conditions, the human sweat also increases [20]. Plaster does not gave significant impact towards air temperature as it shows contrary result against it as shown in Figure 4. From the observation, plaster has a large capillary pores which the water flows more in short period of time and unable to correlate with human sweat rates. This can be proven from Table 2 , which indicate the plaster has more porosity which is $16.7 \%$ from overall volume which has higher porosity rate compare to other porous material. The average evaporation rate for red clay and white clay is $3721.4 \mathrm{Kg} / \mathrm{m}^{2} . \mathrm{m}$ and $736.3 \mathrm{Kg} / \mathrm{m}^{2} . \mathrm{m}$ for 15 minutes interval. However, the porosity test for red clay and white clay has $7.6 \%$ and $2.8 \%$ respectively. It was found that, the more the porosity of the material, the more the evaporation rate is. This result can be justified by the fact that the increase of the porosity increases the permeability of the porous medium, allowing the liquid to permeate faster [11]. As observed in the variance, red clay has close relationship and white clay has slight relationship while plaster has no relationship at all with human sweat evaporation rate. These can be proven through the correlation analysis carried out in the later discussion. As a result, the correlation will provide a clear image as which porous material is significant with human sweating mechanism that is suitable for the preliminary development heat indicator for a new generation of manikin that is suitable in outdoor environments in tropical climate. 


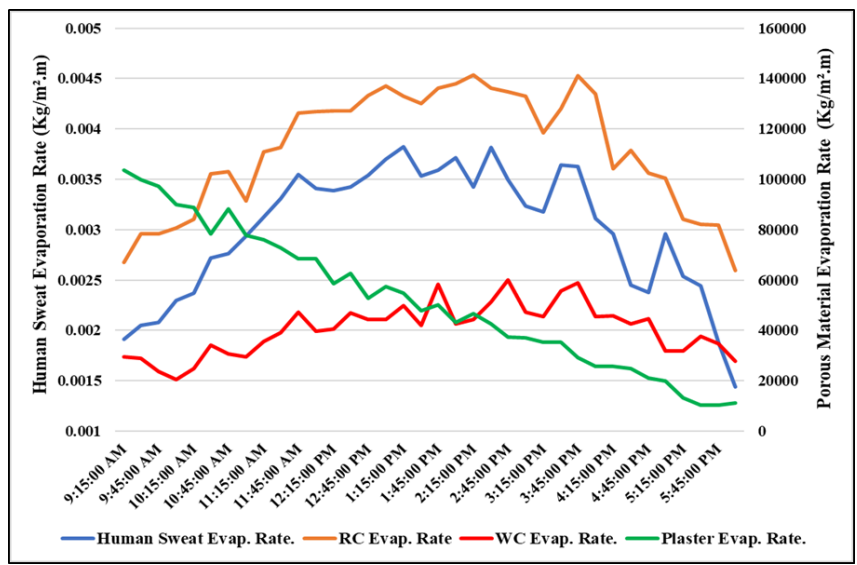

Figure 3: Variation of average value between human sweat and porous material evaporation rate

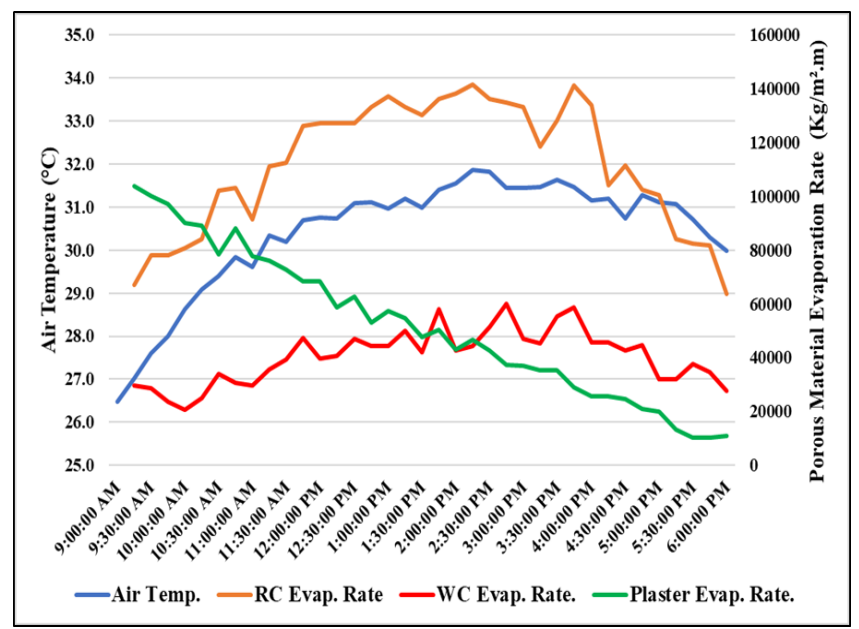

Figure 4: Variation of average value between air temperature and porous material evaporation rate

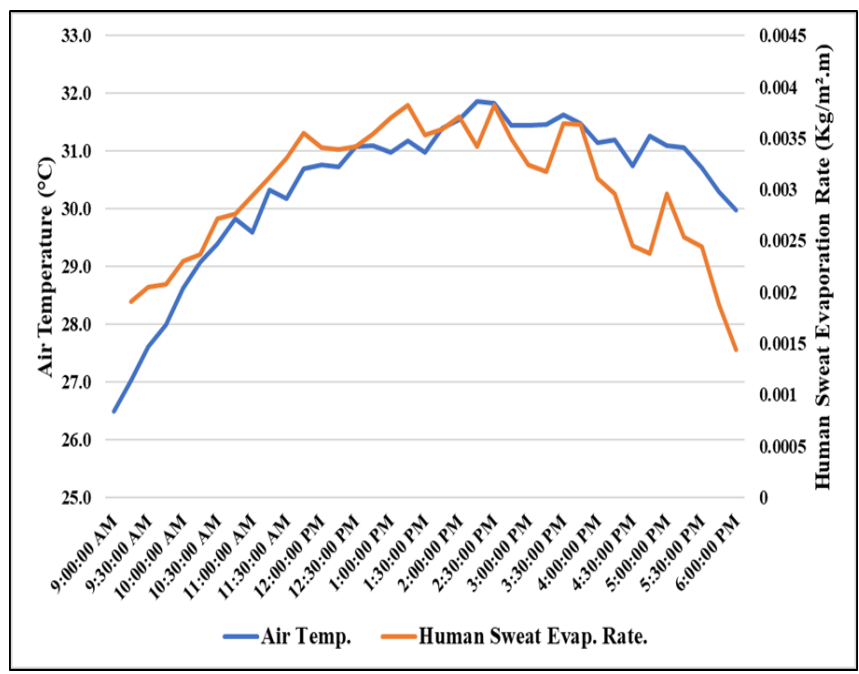

Figure 5: Variation of average value between air temperature and human sweat evaporation rate

\section{Statistical Analysis between Human Sweat and Porous Material Evaporation Rate}

The statistical analysis was carried out using SPSS version 22 to verify the significance between both variable. The Pearson correlation was chosen to evaluate the relationship between human sweat evaporation rate and porous material evaporation rate. Table 6 shows the correlation between human sweat and porous material evaporation rate. The evaporation rate of red clay obtained moderate relationship which was $r=0.583$, $p<0.01$, white clay obtained weak relationship which was $r=0.503, p<0.01$, whereas plaster had very weak correlation $r=0.020$, $p>0.01$ with human sweat evaporation rate as most of the data was randomly distributed.

Table 6: Pearson Correlation between Human Sweat and Porous Material Evaporation Rate Correlation

\begin{tabular}{|c|c|c|c|c|}
\hline \multicolumn{2}{|c|}{} & $\begin{array}{c}\text { Red Clay } \\
\text { Evaporation } \\
\text { Rate }\end{array}$ & $\begin{array}{c}\text { White Clay } \\
\text { Evaporation } \\
\text { Rate }\end{array}$ & $\begin{array}{c}\text { Plaster } \\
\text { Evaporation } \\
\text { Rate }\end{array}$ \\
\hline & $\begin{array}{c}\text { Pearson } \\
\text { Correlation }\end{array}$ & $.583^{* *}$ & $.503^{* *}$ & -0.02 \\
\cline { 2 - 5 } & $\begin{array}{c}\text { Sig. } \\
\text { (2-tailed) }\end{array}$ & 0 & 0 & 0.657 \\
\cline { 2 - 6 } $\begin{array}{c}\text { Sweat } \\
\text { Evaporation } \\
\text { Rate }\end{array}$ & $\mathrm{N}$ & 486 & 486 & 486 \\
\hline
\end{tabular}

**. Correlation is significant at the 0.01 level (2-tailed).

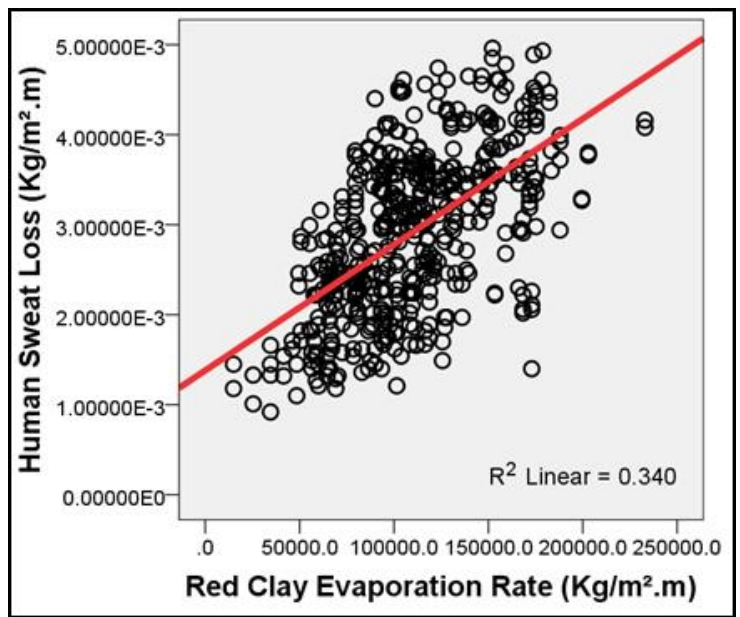

Fig. 4. Linear Relationship between Human Sweat Loss and Red Clay Evaporation Rate

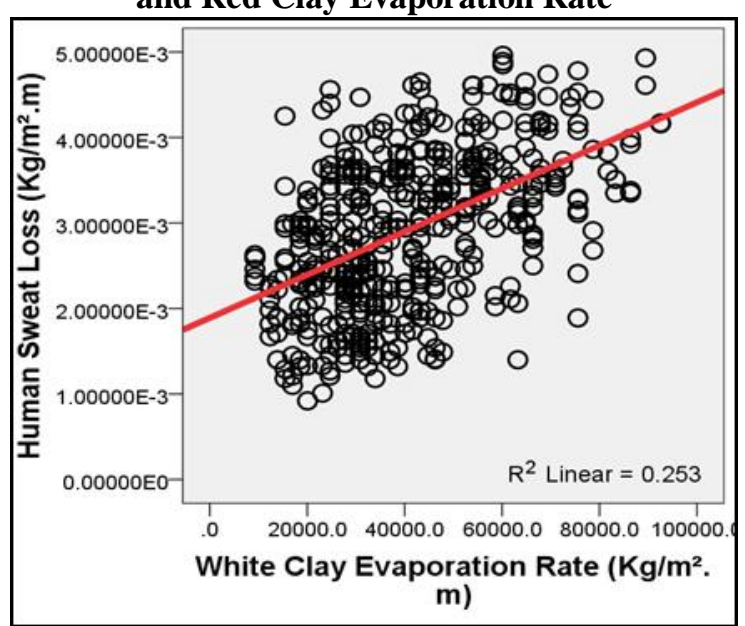

Fig. 5. Linear Relationship between Human Sweat Loss and White Clay Evaporation Rate 


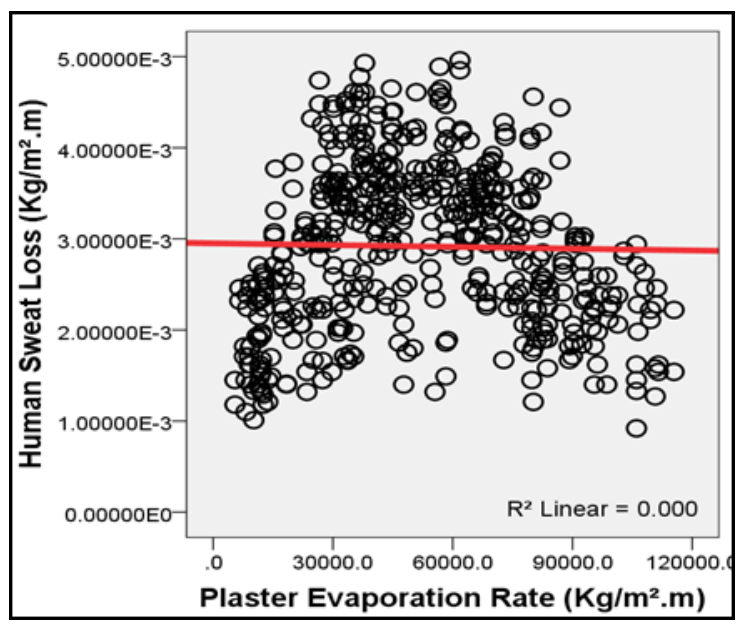

Fig. 6. Linear relationship between human sweat loss and plaster evaporation rate

The coefficient of determination, $\mathrm{R}^{2}$ as shown in Figure 4,5 and 6 displayed a value of red clay (0.340), white clay $(0.253)$ and white clay $(0.000)$. This means that there was a $34.0 \%$ and $25.2 \%$ of variance in human sweat loss that can be explained by the evaporation of red clay and white clay. There was statistically significantly correlated between the porous material and human sweat evaporation rate, except for plaster due to its characteristics. As we link this statistical analysis with previous variation between human sweat and porous material evaporation discussion in Figure 3, red clay has close relationship with human sweat rate compare to other materials, while white clay has seconds close variation with human sweat. It was found that, the variation and statistical analysis relationship have shown the same outcome, and this can be validating that red clay and white clay have shown the capacity to correlate the human sweating rates based on the experiment. From the experimental analysis, it was understood that the preliminary development of new generation of manikin using suitable porous material as a medium for heat response is significantly to be explore in order to find out the relationship between porous material evaporation and human sweating mechanisms. This also stated by [22] which with the development of modern technology, the sweating manikin can be incorporated with a thermoregulatory model, which can predict the dynamic heat and moisture transfer between the human body and the environments, and investigate the impact of thermal environments especially in extreme environments [22]. The evaporation rate of porous material may simulate the human sweat loss as first step or pre-assessment for the indication of impacts in outdoor spaces. This represents a step forward in the simulation of the sweating mechanism. Therefore, sweating can be considered as the preliminary study for the development of human thermal comfort indicator to assess thermal comfort. From this analysis, red clay and white clay may be suitable to become the material in developing for a new generation of manikin that is suitable in outdoor environments. Hence, more research should be conducted using porous material in various location to identify the thermal behavior of the material.

\section{E. Influences from Metabolic Rate, Clothing Insulation and Climatic Variable Factor}

The present study considers from environmental conditions, variety of clothing and different types of metabolic rate. Sweat loss depend on metabolic rate, clothing value and environmental factor [23]. Evaporation rate of porous media are depending on air temperature, wind speed, relative humidity, and sun radiation [24]. Based on the study, in Figure 4 and Figure 5, it can be clearly seen that the evaporation rate of porous material and human sweat loss increased significantly when there is increase in the air temperature. However, activity rate and clothing insulation plays an important role as well in sweating mechanism. From this study, the average metabolic rate for the respondent is recorded at $70 \mathrm{~W} / \mathrm{m}^{2}$ as defined in ASHRAE standard 55-2017 [14]. Meanwhile, for the clothing insulation, the average values were found to be 0.30clo based on ASHRAE standard 55-2017 [14].

\section{CONCLUSION}

This paper presented the investigation of the suitability of porous material such as red clay, white clay and plaster to become that can the material that can simulate human sweating mechanisms. These studies carry out in UTM, Skudai, Malaysia.

Based on the findings in this study, it was found that the red clay and white clay can be a suitable material in simulating human sweating mechanism for thermal comfort evaluation. Red clay and white clay obtained moderate correlation which indicating $\mathrm{r}=0.583$ and $\mathrm{r}=0.503$ respectively and showed good reproducibility and good sensitivity in terms of the response of the evaporation rate to climatic variable. In line with this, human sweat evaporation rate also showed the same sensitivity against surrounding environment. The findings proved that the higher ambient temperature, in results has caused the more human sweat loss and more evaporation rate of porous material.

Therefore, the porous material has a potential to be used as an indicator or tool for finding out the interaction of the human sweat evaporation rate with the outdoor thermal environment. The study shows the correlation of porous material in terms of physiology aspect microclimate environment. It can further used to measure human thermal comfort by correlating with porous material with human psychology aspect. In future, more research to be done to obtain higher correlation between porous material and the human body by modifying the material.

\section{ACKNOWLEDGMENT}

The authors would like to express gratitude to the Malaysian Ministry of Higher Education and Research Management Centre of Universiti Tun Hussein Onn Malaysia for financially support under Postgraduates Research Grants (GPPS) Vote No. U944, TIER 1 grant under Vote No. U843 and to research fund (E15501). 
The support of Faculty of Built Environment, Universiti Teknologi Malaysia is also appreciated.

\section{REFERENCES}

1. Y. Y. Lee, M. F. M. Din, Z. Z. Noor, K. Iwao, S. M. Taib, L. Singh, and E. Aminudin, "Surrogate Human Sensor for Human Skin Surface Temperature Measurement in Evaluating the Impacts of Thermal Behaviour at Outdoor Environment." Measurement: Journal of the International Measurement Confederation, vol. 118, Feb 2018, pp. 61-72.

2. R. Yao, L. Wang, X. Huang, Z. Niu, F. Liu, and Q. Wang, "Temporal trends of surface urban heat islands and associated determinants in major Chinese cities," Sci. Total Environ. Vol. 609, 2017, pp. 742-754.

3. S. Gu, C. Huang, L. Bai, C. Chu, and Q. Liu, "Heat-Related Illness in China, Summer of 2013." International Journal of Biometeorology 60(1), 2016, pp. 131-37.

4. K.C. Parsons, "Assessment of Heat Stress and Heat Stress Indices," In Vogt, J.J. (Ed.) 42. Heat and Cold, Encyclopedia of Occupation Health and Safety. International Labor Organization, Geneva, 2011.

5. H.O. Nilsson, "Thermal comfort evaluation with virtual manikin methods." Building and Environment, 42(12), 2007, pp. 4000 - 4005

6. I. Holmer, "Thermal manikin history and applications," European Journal of Applied Physiology, vol. 92, 2004, pp. 614-618.

7. M. Varheenmaa, "A new generation sweating thermal manikin for the evaluation of the thermoregulation properties of protective clothing," In M. Varheenmaa (Ed.), "Proceedings of the 10th international meeting on thermal manikin and modelling (10I3M)," Tampere, Finland, 2004, pp. $1-5$.

8. Y. Y. Lee, M. F. M. Din, M. Ponraj, Z. Z. Noor, K. Iwao, and S, Chelliapan, "Overview of Urban Heat Island (UHI) Phenomenon towards Human Thermal Comfort." Environmental Engineering and Management Journal, 16(9), 2017, pp. 2097-2112.

9. Rajkishore Nayak and Rajiv Padhye. 2017. Manikins for Textile Evaluation.

10. J. C. A. F. Mendes, and M. C. G. Silva, "On the use of porous materials to simulate evaporation in the human sweating process," European journal of applied physiology, 92(6), 2004, pp. 654-657.

11. Sellami, K., Feddaoui, M., Labsi, N., Najim, M., Oubella, M., \& Benkahla, Y. K. (2019). Direct evaporative cooling performance of ambient air using a ceramic wet porous layer. Chemical Engineering Research and Design, 142, 225-236.

12. N. Makaremi, E. Salleh, M.Z. Jaafar, and A. GhaffarianHoseini, "Thermal Comfort Conditions of Shaded Outdoor Spaces in Hot and Humid Climate of Malaysia." Building and Environment, vol. 48, 2012, pp. 7-14.

13. Malaysian Meteorological Department, Malaysia Weatherwise Malaysia Available at: http://www.met.gov.my

14. ASHRAE. ASHRAE Standard 55-2017, "Thermal environmenta conditions for human occupancy," Atlanta, Georgia, USA: American Society of Heating, Refrigerating and Air-Conditioning Engineering, 2017.

15. ISO. International Standard 7726, thermal environment-instruments and method for measuring physical quantities. Geneva: International Standard Organization; 2002.

16. S. N. Cheuvront, D. A. Goodman, R. W. Kenefick, S. J. Montain, and M. N. Sawka, "Impact of a protective vest and spacer garment on exercise-heat strain,” Eur J Appl Physiol vol. 102, 2008, pp. 577-583.

17. Shokri, N., Lehmann, P., \& Or, D. (2010). Evaporation from layered porous media. Journal of Geophysical Research: Solid Earth, 115(6), $1-12$.

18. Aboufoul, M., Shokri, N., Saleh, E., Tuck, C., \& Garcia, A. (2019) Dynamics of water evaporation from porous asphalt. Construction and Building Materials.

19. Roy Choudhury, A. K., Majumdar, P. K., \& Datta, C. (2011). Factors affecting comfort: human physiology and the role of clothing. Improving Comfort in Clothing. Elsevier Masson SAS

20. Arens, E. \& Zhang, H. (2006). The skin's role in human thermoregulation and comfort. Thermal and Moisture Transport in Fibrous Materials.

21. Chen, W. (2011). Thermal analysis on the cooling performance of a wet porous evaporative plate for building. Energy Conversion and Management, 52(5), 2217-2226.

22. Lu, Y., Kuklane, K., \& Gao, C. (2017). Types of thermal manikin. Manikins for Textile Evaluation. Elsevier Ltd.

23. Y. Shapiro, K. B. Pandolf, and R. F. Goldman, "Predicting sweat loss response to exercise, environment and clothing," Eur J Appl Physiol, vol. 48, 1982, pp. 83-96.

24. H., K. Davarzani, R. M. Smits, Tolene, and T. Illangasekare, "Study of the effect of wind speed on evaporation from soil through integrated 